Darstellung chemisch reiner Paraoxybenzoësäure durch Umwandlung der Salicylsäure;

\author{
mitgetheilt \\ von
}

H. Kolbe.

Im Verlaufe der Untersuchungen über Salicylsänre und verwandter Verbindungen, welche eben in meinem Laboratorium ausgefilhrt werden, hat mein Assistent, Herr H. Ost, die interessante Beobachtung gemacht, dass trocknes neutrales kalicylsaures Natron beim Erhitzen in einer Retorte auf ohngefähr $220^{\circ}$ eine einfache glatte Zersetzung erfährt in der Weise, dass zwei Moleküle jenes Salzes geradeauf zerfallen in $1 \mathrm{Mol}$. Phenol, $1 \mathrm{Mol}$. Kohlensäure und $1 \mathrm{Mol}$. natrinm-salicylsaures Natron, das sog. basische Aalz der Salicylsăure, im Sinne folgender Gleichung:

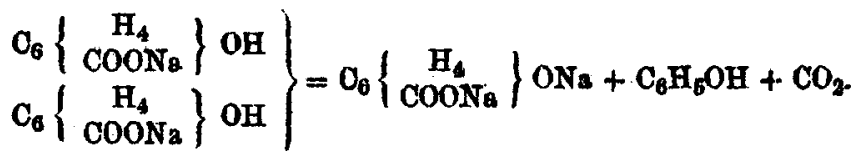

Man gewinnt also genau die Hälfte der verbrauchten Salicylsăuro wieder. Das abdestillirende ganz reine Phenol erstarrt so schnell zu einer schönen weissen Krystallmasse, dass davon der Retortenhals sich leicht verstopft.

Als $\mathrm{Hr}$. Ost trocknes neutrales salicylaanres $\mathrm{K}_{\mathrm{a}} \mathrm{li}$ in einer Retorte auf $220^{\circ}$ erhitzt, und so lange auf dieser Temperatur erhalten hatte, bis kein Phenol mehr überging, zeigte sich bei fast ganz gleichem Verlauf des Processer, dass die rückständige Salzmasse keine Spur Salicylsäure mehr enthielt, sondern aus kalium-paraoxybenzoësaurem Kali bestand. Die Paraoxybenzoëtänre, welche nach Auflösen dieses Salzes in Wasser auf Zusatz von Salzbăure niederfällt, ist meist dunkel gefărbt, lrann aber durch einen einfachen Reinigungsprocess leicht schneeweiss und chemisch rein erhalten werden. 
Von allen Metboden zur Darstellung der Paraoxybenzoësäure ist diese jetzt, wo die Salicylsäure so leicht $2 \mathfrak{n}$ beschaffon ist, entschieden die beste.

Hr. Ost hat die experimentelle Beantwortung der Frage in Angriff genommen, ob ausser dem Kulisalze der Salicylsäure noch andere Metallsalze resp. das des Tetraäthylammoninmoxyds beim Erhitzen Paraoxybenzoësäure liefern, und hat bis jetzt gefunden, dass der salicylsaure Baryt, Strontian, Kalk und das Magnesiasalz sich ganz gleich dem Natronsalze verbalten.

Obige Erfahrung verspricht den Sohlüssel zu manchen oinander widersprechenden Angaben verschiedener Chemiker über die Natur der Producte zu liefern, welche sio durch Erhitzen der nämlichen Substanz mit Kalihydrat gewonnen baben. So behauptet, um ein Beispiel anzuführen, der eine Chemiker, aus Chlor phenol durch Schmelzen mit Kalihydrat Resorcin, der andere ans demselben Chlorphenol Hydrochinon erhalten $2 \mathrm{n}$ haben. Sollte der eine von beiden etwa Natronhydrat statt Kalihydrat, oder ein natronhaltiges Kalibydrat angewandt haben? Oder sollten beide zwar mit demselben Material gearbeitet, aber auf verschieden hohe Temperaturen erhitzt haben?

Ich lasse eben Versuche darüber anstellen, ob ein und dasselbe Chlorphenol beim Erhitzen ein Mal mit Kalihydrat und sodann mit Natronhydrat auf gleiche Temperaturen die nämlichen oder, wie ich vermuthe, verschiedene Produkte liefert.

Dass die Temperatur bei diesen Realtionen anf die Natur der Produkte von Einfluss sein kanu, darauf weist die unlängst von mir veröffentlichte Beobachtung ${ }^{1}$ ) hin, welche Hr. Hartmann in meinem Laboratorium gemacht hat, dass nämlich trooknes Phenolkali durch Erhitzen in Kohlensäurestrom auf $145^{\circ}$ Salicylsänre liefert, aber über $200^{\circ}$ Paraoxybenzoësäure giebt.

Ob obige Thatsachen geeignet sind, der auf so schwachen Füssen stehenden Methode der Ortsbestimmang sub-

1) Dies. Journ: [2] 10, 99 und 100 . 
26 Laspeyres: Ueber die quantitative Bestimmung

stituirender Flemente in der Benzolderivaten eine Stütze zu gewähren, oder ihre für mich schon längst unzweifelhafte Bodenlosigkeit zu vermehren, darüber zu discutiren will ich den Chemikern uberlassen, welche in dieser Art metaphysischer Speeulationen Uebung besitzen.

Leipzig, 1. Januar 1875.

\section{Ueber die quantitative Bestimmung des Wassers;}

ron

\section{H. Laspeyres in Aachen.}

Bei den Untersuchungen über den Gehalt an Wasser, bezüglich an Wasserstoff, in anorganischen Verbindungen, namentlich in Mineralien, welche mich schon seit längerer Zeit beschäftigen ${ }^{3}$ ) und mir vielo Schwierigkeiten in der praktischen Ausführung za überwinden geben, stiess ich wiederholt auf Beobachtungen, welche unter sich übereinstimmten, aber durchaus nicht mit dem, was zu erwarten stand.

Diese Beobaichtungen liessen sich nur erklären bei der Annahme, dass die bisher üblichen Methoden, das Wasser quantitativ zu bestimmen, nicht zuverlássig genug wären.

Whe ich meine Untersuchungen fortsetzen konnte, musste ich deshalb diese Methoden mit möglichster $\mathrm{Ge}_{8-}$ nauigkeit und von allen Seiten prüfen. In dem vergangenen Sommer habe ich mich dieser Arbeit in vielen Versuchsreihen unterzogen, von denen ioh auf den folgenden Seiten nur einige als Belege für den Gang und die Resaltate meiner Beobachtangen mitzutheilen brauche, weil sie alle gut unter sich übereinstimmen, und weil nie eine

1) Neues Jahrbuch f. Mineralogie a. s. w. 1873. 8. 159 ff. Tschermak's Mineralogische Mittheilungen III. 1873. S. $147 \mathrm{ff}$ Dies. Journ. [2] 7, 278 ff. - Pogg. Ann. 1874. 152, 132 ff. 